\title{
PREPARATION AND DISCHARGE CHARACTERISTICS OF SOLID REDOX POLYMERIZATION ELECTRODES EMPLOYING DISULFIDE POLYMERS AND COPOLYMERS.
}

\author{
M. M. LERNER*, S. J. VISCO ${ }^{\star \star}$, M. UE ${ }^{\star \star \star}$, M. M. DOEFF ${ }^{\star \star}$, AND L. C. DEJONGHE \\ ${ }^{*}$ Department of Chemistry, Oregon State University, Corvallis, OR 97331-4003 \\ ${ }^{\star \star}$ Materials Sciences Division, Lawrence Berkeley Laboratory, University of California, Berkeley, CA 94720

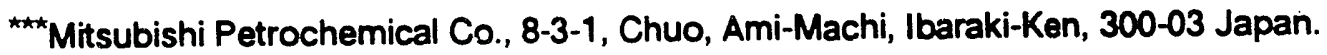

\section{ABSTRACT}

Recent work in our laboratory on polymeric organodisulfides has shown these materiais to perform well as positive electrodes in solid-state batteries. The polymeric materials have been named solid redox polymerization electrodes (SRPE's) due to the reversible polymerization/depolymerization reaction that occurs on charge/discharge of the electrode. The cell reaction for SRPE-based cells can be described for a simple case as, $2 n M+(S R S)_{n}=n M_{2} S R S$, where $M$ is an alkali metal $(L i, N a, K)$ and $R$ is an organic group. In the broader sense SRPE's can have more than two $S$ groups per monomer $R$ unit, and are reversible to other monowalent and divalent metals. In the fully charged state SRPE's consist of polydisulfide polymers and are depolymerized on discharge by scission of sulfur-sulfur bonds, leading to the formation of dithiolate salts in the fully discharged cell. SRPE's are easy to synthesize, are air stable, and should be very inexpensive in bulk quantities. Depending on the redox potential of the polydisulfide and reaction conditions, many disulfides can be copolymerized by oxidizing a mixture of dithiols, $x$ HSRSH + yHSR'SH $+(x+y) I_{2}=(S R S)_{x}(S R ' S)_{y}+2(x+y) H$, allowing modification of the physical and/or redox properties of the SRPE's. A series of simple aliphatic dithiols including $\left(\mathrm{HSCH}_{2} \mathrm{CH}_{2} \mathrm{SH}\right),\left(\mathrm{HSCH}_{2} \mathrm{CH}_{2} \mathrm{OCH}_{2} \mathrm{CH}_{2} \mathrm{SH}\right)$, and $\left(\mathrm{HSCH}_{2} \mathrm{CH}_{2} \mathrm{SCH}_{2} \mathrm{CH}_{2} \mathrm{SH}\right)$ have been oxidized to polydisulfides and mixtures of the dithiols have been copolymerized. All of the resulting polymers and copolymers were evaluated in solid-state lithium cells, with some of the new materials demonstrating high levels of performance. The utilization of available capacity in the positive electrod $\epsilon$ was observed to be independent of electrode thickness for a number of SRPE's at loading levels up to $45 \%$ by weight. At $90^{\circ} \mathrm{C}$, relatively thick positive electrodes based on $\left(\mathrm{SCH}_{2} \mathrm{CH}_{2} \mathrm{~S}\right)_{n}$ have been discharged to surface capacities of over 20 coulombs $/ \mathrm{cm}^{2}$ at a current density of $0.5 \mathrm{~mA} / \mathrm{cm}^{2}$. The discharge profiles for most of the aliphatic polydisulfides are exceedingly flat at slightly over 2 volts versus lithium. Although other polydisulfides such as those derived from the dithiazoles exhibit higher cell voltages, the low equivalent weight of materials such as $\left(\mathrm{SCH}_{2} \mathrm{CH}_{2} \mathrm{~S}\right)_{n}$ [46 g/equiv] and the low cost of such polymers indicates a potential for commercial application.

\section{PMSTER}

This research was supported by the Assistant Secretary for Conservation and Renewable Energy, Deputy Assistant Secretary for Utility Technologies, Office of Energy Management, Advanced Utility Concepts Division of the U.S. Department of Energy under Contract No. DE-AC03-76SF00098. 


\section{INTIRODUCTION}

Recent work in this laboratory has focussed on the electrochemical properties and charge/discharge characteristics of the organodisulfide/dithiolate redox couple[ [i-3]. There is potential for developing practical devices based on this chemistry; polymeric organodisulfides have been shown to perform well as positive electrodes in solid-state batteries[4,5]. The poly(organodisulfides) have been termed "solid redox polymerization electrodes (SRPE's)" due to the reversible polymerization/depolymerization that occurs on charge/discharge in a reaction cell.

The general redox process for SRPE-based cells is described by (1):

$$
x n M+(S R S)_{n}=n M_{x} S R S
$$

As a large number of disulfides are readily prepared[6] and the choice of metal not restricted by topological effects (as in an intercalation process), the number of realizable reactions conforming to (1) is very large indeed. Initial studies have concentrated on relatively simple poly(organodisulfides) and $M$ $=\mathrm{Li}$ and $\mathrm{Na}$. More generally, SRPE's may include more complex poly(organodisulfides), such as copolymers containing disulfide linkages and/or polymers containing more than two disulfides per organic moiety. In addition, SRPE's may be reversible to a number of monovalent or higher valent metals.

The physical and electrochemical properties of the poly(organodisulfide) are of primary concern in the theoréical capacity and energy densities, performance, and fabrication of these cells. The remarkable influence of the organic moiety on cell potential and discharge characteristics has already been described [4]. Poly(organodisulfides) are typically easy to prepare, air stable and inexpensive (all very desirable properties for commercial applications), and as noted above, numerous. The systematic examination of new SRPE's may therefore optimize other useful properties such as (1) low equivalent weight (for high energy and capacity densities), (2) rapid electrode kinetics at moderate temperatures, (3) high ionic diffusivities (to minimize polarization effects), and (4) processability.

In the present study, a number of organodisulfide polymers and copolymers were examined as SRPE's in lithium cells. Certain desirable traits described above were simple to incorporate. For instance, poly(etl ylene disulfide), $\left(\mathrm{SCH}_{2} \mathrm{CH}_{2} \mathrm{~S}\right)_{n},(X 8)$ has a low equivalent weight $(46 \mathrm{~g} / \mathrm{mole})$, and therefore has a high theoretical energy' density (see Table 1). Poly(ethyl ether disulfide), $\left(\mathrm{SCH}_{2} \mathrm{CH}_{2} \mathrm{OCH}_{2} \mathrm{CH}_{2} \mathrm{~S}\right.$ ) has advantageous physical properties, being an amorphous, nearly colorless, soluble polymer[7]. Thiokol (Morton Thiokol, Inc.) is an inexpensive commercial product, and was also examined in SRPE's. While the detailed chemical composition is unavailable, Thiokol is mainly composed of poly(ethyl ether disulfide) and structurally related disulfides. Copolymers were also prepared to obtain properties such as increased hardness via cross-linking. 


\section{EXPERIMENTAL}

2,5-dimercapto-1,3,4-thiadiazole (Aceto Corp.), 2,4-Dithiopyramidine (Sigma), 2-mercaptoethyi ether (Aldrich, tech. grade), 2-mercaptoethyl sulfide (Aldrich, 95\%), trithiocyanuric acid (Aldrich, 95\%), 1,2 ethanedithiol (Aldrich, 99\%), thiokol (Morton Thiokol, Inc.), $\mathrm{K}_{3} \mathrm{Fe}(\mathrm{CN})_{6}$ (Aldrich, 99+\%), $\mathrm{LiOH} \cdot \mathrm{H}_{2} \mathrm{O}$ (Aldrich, $99.9+\%$ ), $\mathrm{I}_{2}$ (Baker, sublimed), and $\mathrm{CH}_{3} \mathrm{CN}$ (Aldrich, HPLC grade) were used as supplied. Poly(ethylene) oxide (avg $\mathrm{mw}=5 \times 10^{6}$, Aldrich), C black (Shawinigan acetylene black, Chevron) and $\mathrm{LiSO}_{3} \mathrm{CF}_{3}$ were dried under vacuum at $50^{\circ} \mathrm{C}$ for several days and stored under an inert atmosphere. Lithium foil of approximately 5 mil thickness (Lithco Co, battery grade) was stored under helium and cut into disks (18 $\mathrm{mm}$ diameter) prior to use.

The preparation of disulfide polymers and copolymers involved the formation of a soluble lithium salt of the dithiol and subsequent oxidation of the dithiolate to precipitate the disulfide polymer. The general preparative method is illustrated by the following reactions:

$$
\begin{gathered}
\mathrm{HSRSH}+2 \mathrm{LiOH}(\mathrm{aq})=\mathrm{Li}_{2} \mathrm{SRS}(\mathrm{aq})+2 \mathrm{H}_{2} \mathrm{O} \\
n \text { SRS}^{2-}(\mathrm{aq})+2 \mathrm{n} \mathrm{Fe}(\mathrm{CN})_{6}{ }^{3-}(\mathrm{aq})=(\mathrm{SRS})_{n}(\mathrm{ppt})+\mathrm{Fe}(\mathrm{CN})_{6}{ }^{4-}(\mathrm{aq})
\end{gathered}
$$

This two-step method is quite simple and usually preferable as some of the dithiols are themselves somewhat difficult to handle even in a well-ventilated hood (stench). in contrast, the aqueous dithiolate solutions have little or no odor and, in the case of copolymerizations, insure a homogeneous phase prior to oxidation. Notably, for the $c_{\lrcorner}$se of nitrogen containing compounds such as the dimercaptodithiazoles, the starting mercaptans have no discernable smell at all. All reactions proceeded rapidly under ambient conditions in aqueous solution. Copolymers were prepared by a similar method using an appropriate combination of dithiols in (2a). The resultant polymers or copolymers were washed copiously with deionized water and a suitable organic solvent and then dried in vacuo at $50^{\circ} \mathrm{C}$.

Positive electrodes were prepared from a mixture of the disulfide polymer (30 or $45 w t \%)$, carbon black (7-10wt \%), carbon dispersant (2 - $3 w t \%)$, and remainder poly(ethylene) oxide. A viscous slurry, typically $2-3 \mathrm{wt} \%$ total solids, was obtained in $\mathrm{CH}_{3} \mathrm{CN}$ by vigorous stirring for several days followed in some cases by use of a high-speed homogenizer (Tekmar). The homogeneity of the dispersion was found to correlate strongly with the performance of the films produced. Films of $20-80 \mu \mathrm{m}$ thickness were cast and air-dried on a clean Teflon surface, cut into disks (area $=2.0 \mathrm{~cm}^{2}$ ), and dried in vacuo for several days at $50^{\circ} \mathrm{C}$. $\mathrm{PEO}_{8} \mathrm{LiSO}_{3} \mathrm{CF}_{3}$ electrolyte films $(30-50 \mu \mathrm{m}$ thickness) were prepared by a similar method.

Test cells (see Fig. 1) were assembled under an inert atmosphere and discharged at $90-95^{\circ} \mathrm{C}$. The $\mathrm{Li}$ electrode capacity in all cells exceeded that of the positive electrode by more than $400 \%$ (by stacking $L i$ foils if necessary) and therefore did not limit cell performance. Discharge and cycling characteristics were examined with a PAR 173 or 371 potentiostat/galvanostat utilizing software developed in this laboratory[7]. Cell impedances (typically $\approx 20-30 \Omega \mathrm{cm}^{2}$ ) were determined in situ by a pulse technique described elsewhere[8]. Large cell impedances $\left(>75 \Omega \mathrm{cm}^{2}\right)$ occasionally resulted from inhomogeneous cathode films or poor contact between cell components (high interfacial impedance), and these cells generally showed poor discharge behavior. Galvanostatic cell discharge was performed at $1 \mathrm{~mA}(0.5$ $\mathrm{mA} / \mathrm{cm}^{2}$ ) with cell OCV's monitored periodically. 


\section{RESULTS}

Structures, equivalent weights, and OCV's are listed in Table 2. The X1 polymer was obtained as a free-flowing off-white to yellow powder. The $X 7, X_{8}$, and $X 9$ polymers were white powders, and $X 0$ was a colorless or faint yellow, amorphous, highly viscous, polymer.

Copolymers were prepared by the oxidation of an appropriate combination of dithiolates in aqueous solution. In some syntheses, inhomogeneous products were obtained which clearly involved a mixture of two polymeric phases. For example, the attempted copolymerization of $50 \%$ X0 with $50 \%$ X5 produced a white powder along with a tacky, translucent polymer. In other reactions, homogeneous products with physical properties dissimilar to either of the pure polymers resulted. These were therefore taken to be true copolymers. The addition of $5 \%$ by weight $X 5$ to $X 0$ resulted in a single-phaje polymer which was harder and considerably easier to handle than pure X0 polymer. A 50\% X0 / 50\% X1 combination resulted in a yellow-white powder similar in appearance to the pure $X 1$ polymer. Products obtained were not directly identified as block, regular, or random copolymers (Fig. 2).

Discharge profiles are given in Figures $3-5$. Charge efficiency was based on the theoretical capacities derived by weighing the cathode films, and varied from $45 \%(X 7)$ to more than $80 \%(X 1)$. Theoretical capacities are shown for each curve. Figure 3 gives discharge profiles for the $X 7, \times 8$, X9, and Thiokol polymers. Figure 4 shows the effect of stacking cathode films in Li/PEO $8 \mathrm{LITf} / \mathrm{X} 8$ cells. Figure 5 shows discharge profiles for the $X 0$ and $X 1$ polymers and copolymers with $50 \% \times 0 / 50 \% \times 1$, and $95 \% \times 0 / 5 \% \times 5 \times 5$ = trithiocyanuric acid).

\section{DISCUSSION}

The effect of the organic moiety of the poly(organodisulfide), $R$ in (SRS) $n$, on the discharge voltage in $\mathrm{Li} / \mathrm{Li}+$ electrolyte/disulfide cells has been noted previously $[4,5]$, and further illustrated by these data. Poly (organodisulfides) containing $-\mathrm{N}=\mathrm{CR}$ '-S-S- linkages $(X 1, X 7)$ have discharge plateaus near $2.6-2.7 \mathrm{~V}$, those with - $\mathrm{CR}_{2}{ }_{2}-\mathrm{CR}^{\prime \prime}{ }_{2}-\mathrm{S}$-S- linkages $(\mathrm{X0}, \mathrm{X8}, \mathrm{X9})$ discharge at $2.0 \mathrm{~V}$. The latter class of polymers often give initial OCV's which are some $0.5 \mathrm{~V}$ higher, but these potentials fall rapidly upon discharging the cell.

The $\mathrm{X} 8$ polymer shows a flat discharge plateau with discharge efficiencies typically above $60 \%$ for either $30 \%$ or $45 \%$ loadings. As seen in Figure 4 , the stacking of $X 8$ cathode films does not impair cell performance, and $>20 \mathrm{C} / \mathrm{cm}^{2}$ was drawn at $0.5 \mathrm{~mA} / \mathrm{cm}^{2}$ when 3 cathode films were stacked. Initial studies on deep charge/discharge cycling of $X 8$-based cells do not show the high cycle life and reversibility observed in X1-based cells; the X8-based cells generally lost $\approx 10 \%$ discharge capacity per cycle. The cycling results may be significantly improved after further testing and modification these cells.

Table 2 gives theoretical coulometric and gravimetric film capacity and energy densities for cathode films containing $X 0, X 1$ and $X 8$. The values derived illustrate that the very low equivalent weight of the $X 8$ polymer ( $42 \mathrm{~g} / \mathrm{mole}$ ) compensates for its lower discharge voltage ( $2 \vee$ vs $3 \vee$ for $X 1$ ), resulting in similar energy densities for $X 1$ and $X 8$ - Jased cathode films. Due to the greater equivalent weight of $X 0$, these polymer films have lower theoretical energy densities. Copolymers produced from $95 \%$ XO monomer and $5 \% \times 5$ monomer (trithiocyanuric acid) are easier to handle than the $\mathrm{XO}$ polymer, and the discharge 
characteristics were nearly identical (see Figure 5). Cathode films containing the $X 1$ / $X 0$ copolymer have a discharge profile like that of $\times 1$-based films, but exhibit a more gradual decrease in potential at the end of the discharge. Thiokol-based cathode films (see Figure 3) performed almost as well as the polymers prepared by us, and clearly show the multiple discharge plateaus characteristic of a mixture of disulfides or block copolymer. The facile modification of discharge profiles and physical properties by employing copolymers or a combination of disulfides will likely be a desirable feature of SRPE-based cells. Research is presently being pursued in two major areas; (1) the investigation of the cycling characteristics and stability 'of these cells, and (2) the fabrication of ambient temperature cells by incorporating amorphous polymer binders and electrolytes.

\section{ACKNOWLEDGEMENTS}

The authors wish to acknowledge Aceto Co. for supplying 2,4-dimercapto-1,3,5-dithiazole and Chevron Chem. Co. for supplying acetylene black. This research was supported by the Assistant Secretary for Conservation and Renewable Energy, Deputy Assistant Secretary for Utility Technologies, Office of Energy Management, Advanced Utility Concepts Division of the U.S. Department of Energy under Contract No. DE-AC03-76SF00098. M.L. acknowledges support by an NSF Postdoctoral Fellowship.

\section{REFERENCES}

1. S.J. Visco, C.C. Mailhe, L.C. DeJonghe, and M.B. Armand, J. Electrochem. Soc., 136, 661 (1989).

2. M. Liu, S.J. Visco, and L.C. DeJonghe, J. Electrochem. Soc., 136, 2570 (1989).

3. M. Liu, S.J. Visco, and L.C. DeJonghe, J. Electrochem. Soc., 137, 750 (1990).

4. S.J. Visco, M. Liu, M.B. Armand, and L.C. DeJonghe, Mol. Cryst. Liq. Cryst., 190, 185 (1990).

5. M. Liu, S.J. Visco, and L.C. DeJonghe, Proc. Electrochem. Soc. Symp., October, 1989.

6. L. Field, in "Organic Chemistry of Sulfur" ed. by S. Oae, Plenum Press: New York, 1977.

7. "Handbook of Common Polymers", Roff and Scott, 1971.

8. S.J. Visco and M. Liu, submitted to J. App. Electrochem. 


\section{Table I}

\section{Table II}

Figure 1. Experimental cell for evaluating SRPE's in solid-state lithium batteries.

Figure 2. Various types oi copolymers that might be formed by oxidation of mixtures of dithiolates (-SRS') having different organic $R$ groups.

Figure 3. Discharge characteristics for X7, X8, X9, and Thiokol polymers (table I) in solid-state lithium cells.

Figure 4. The effect of stacking cathode films in the Li/PEO $8 \mathrm{~L} T \mathrm{Tf} / \mathrm{X} 8$ battery.

Figure 5. Discharge profiles for $X 0$ and $X 1$ polymers, and copolymers composed of $50 \% \times 0 / 50 \% \times 1$, and $95 \% \times 0 / 5 \% \times 5$ (where $\times 5$ = trithiocyanuric acid). 


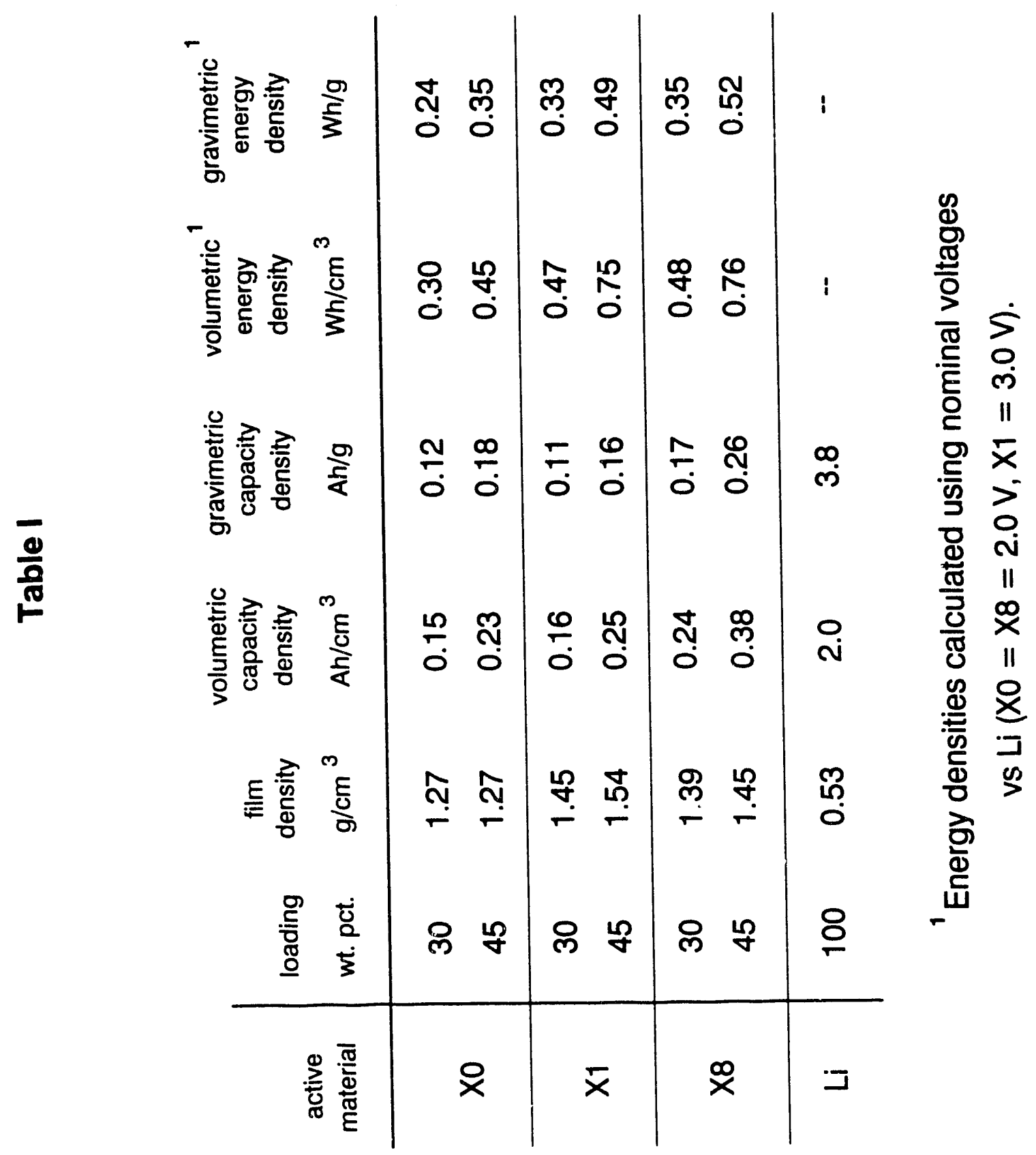




\section{Table II}

formula (notation) name eq. wt.

(g/mole)

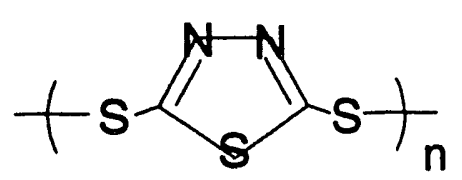

$$
\begin{aligned}
& \begin{array}{ll}
74.1 & 3.0
\end{array} \\
& \text { 2,4-dithiopyrimidine } \quad 59.2 \quad 2.5-2.8 \\
& +{ }^{s} O_{N}^{s+t_{n}} \\
& \text { (X7) }
\end{aligned}
$$

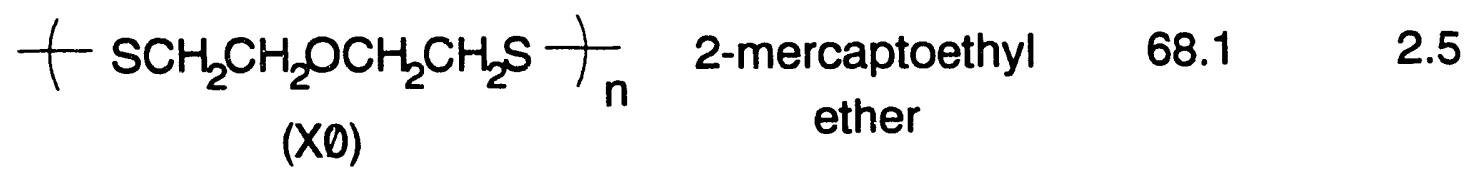

$$
\begin{aligned}
& \begin{array}{cccc}
\left(\mathrm{SCH}_{2} \mathrm{CH}_{2} \mathrm{SCH}_{2} \mathrm{CH}_{2} \mathrm{~S}\right)_{n} & \begin{array}{c}
\text { 2-mercaptoethyl } \\
\text { sulfide }
\end{array} & 76.2 & 2.3 \\
& \text { (X9) } &
\end{array} \\
& \text { t } \left.\mathrm{SCH}_{2} \mathrm{CH}_{2} \mathrm{~S}\right)_{\mathrm{n}} \quad \text { 1,2-ethanedithiol } 46.1 \quad 2.3-2.8
\end{aligned}
$$




\section{Battery test cell (exploded view)}

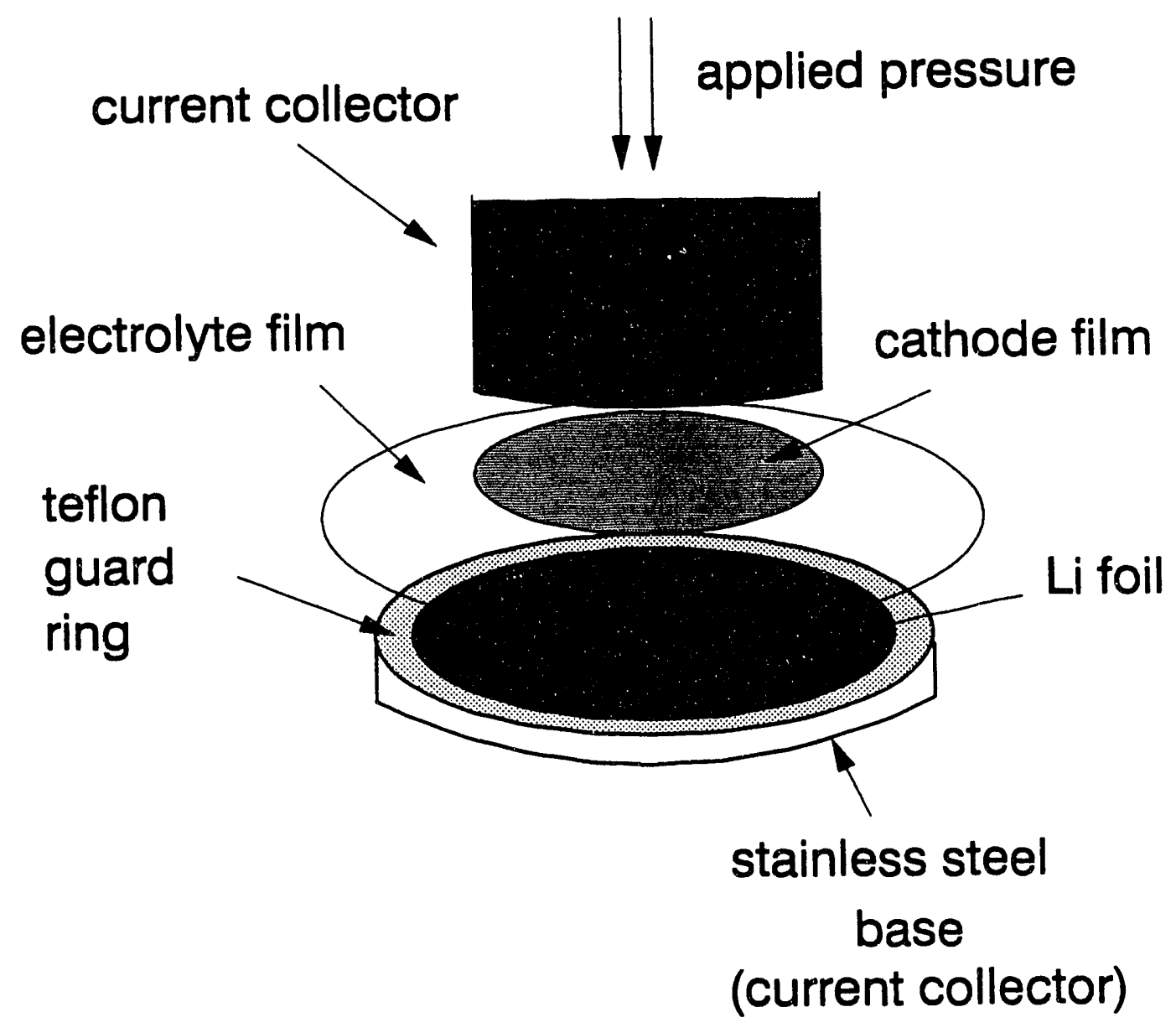

Figure 1. Experimental cell for evaluating SRPE's in solid-staie lithium batteries. 

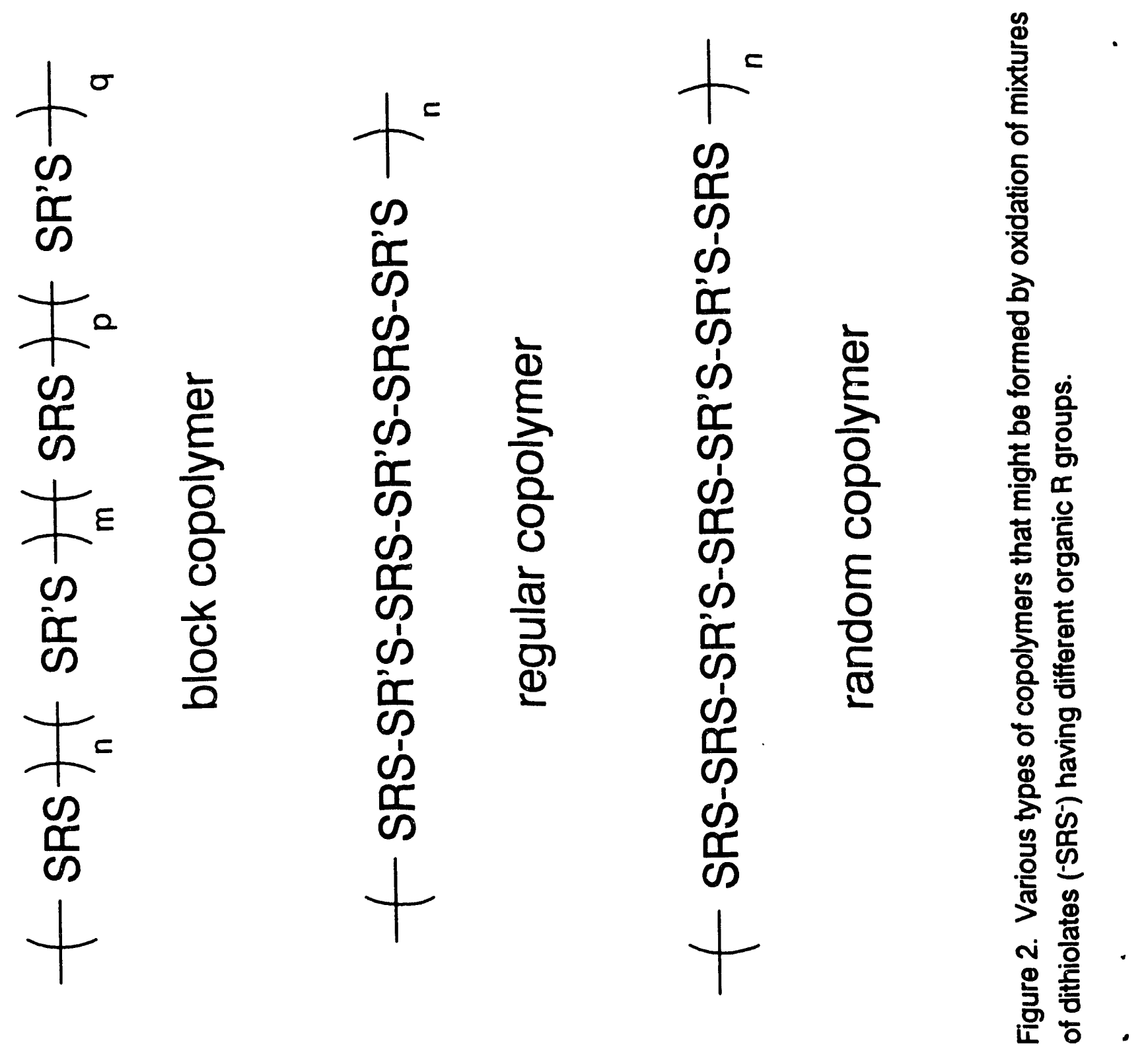


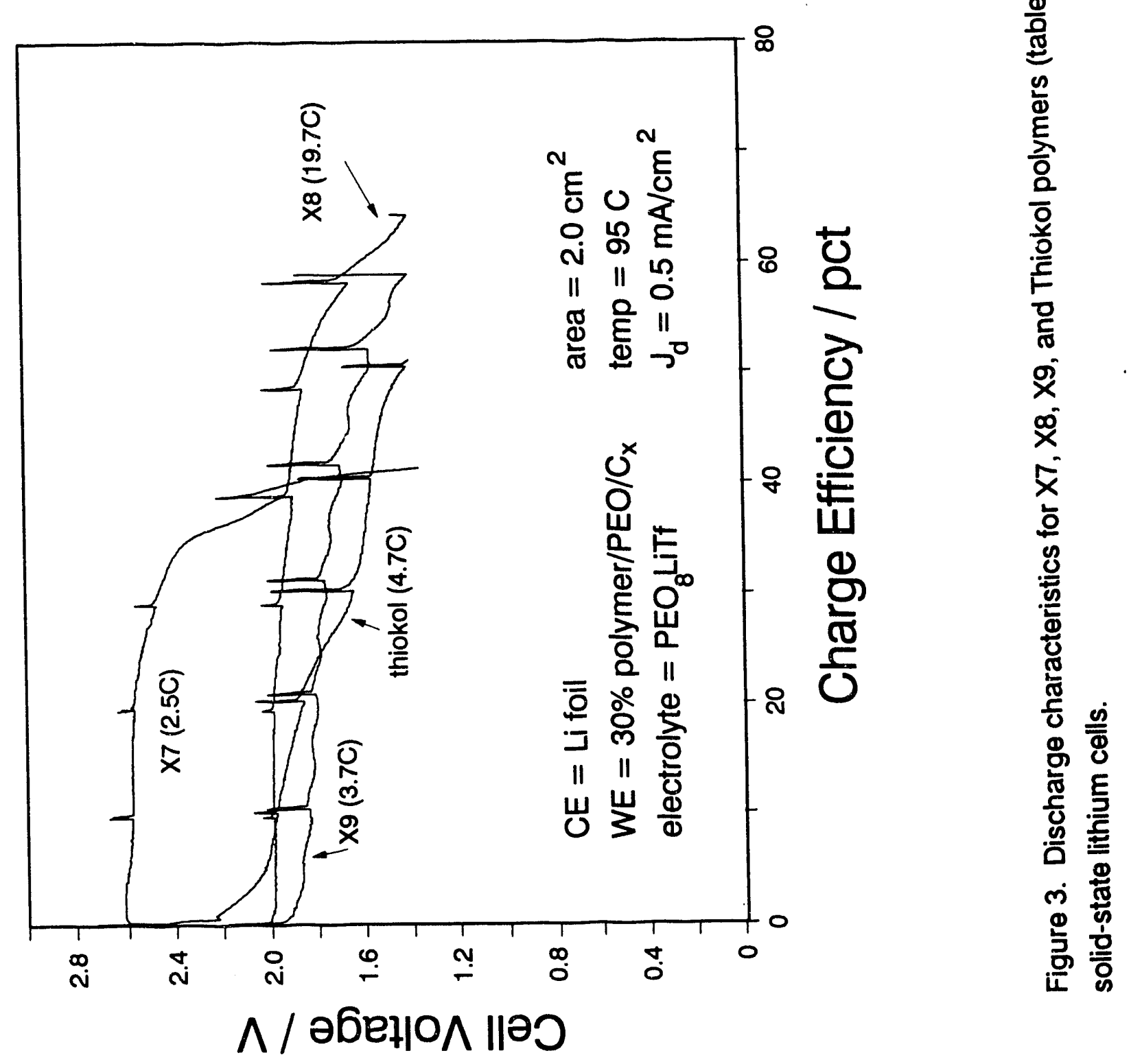




\section{Discharge curves for X8 multilayer cathodes}

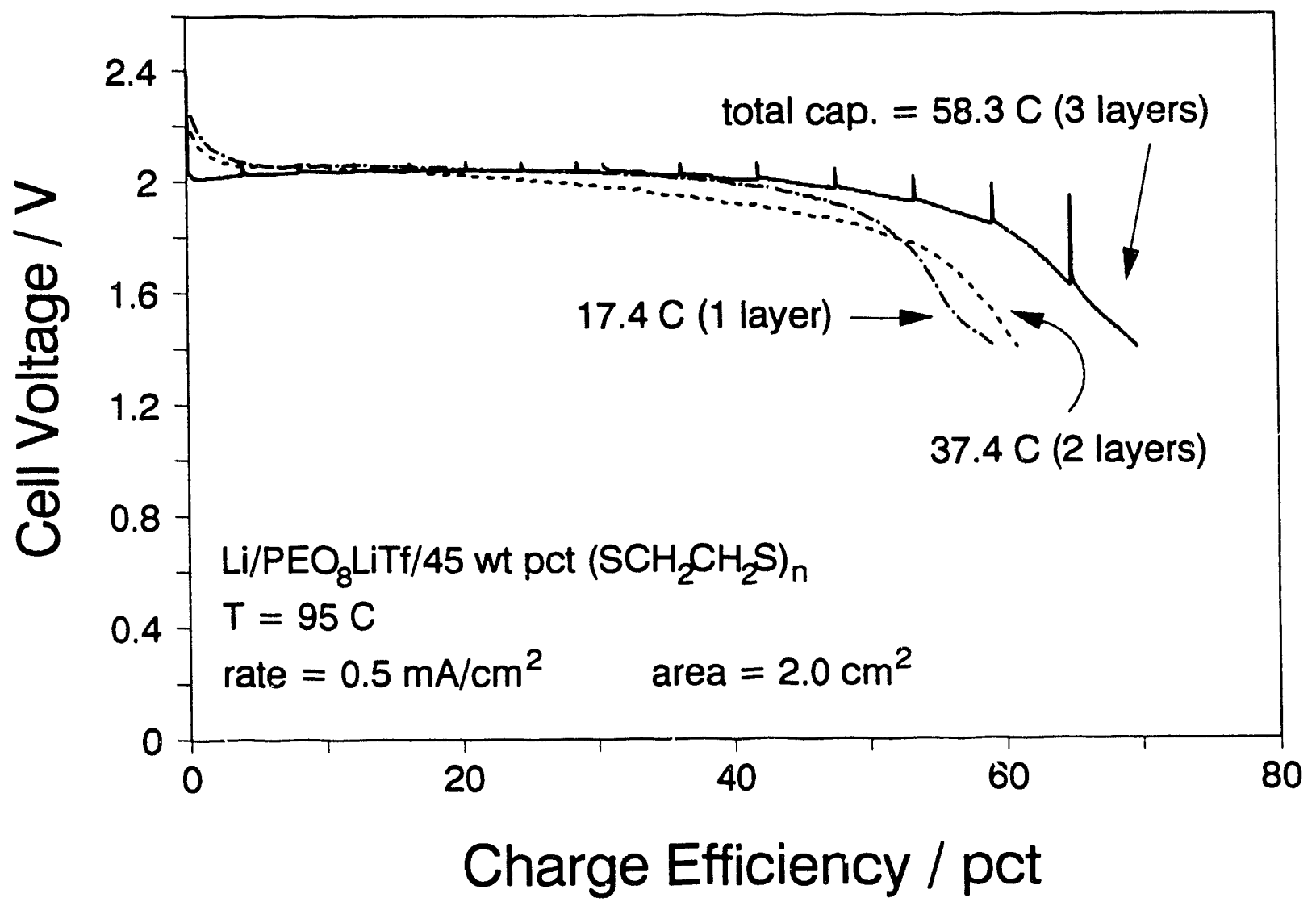

Figure 4. The effect of stacking cathode films in the Lن/PEO ${ }_{8} L \mathrm{LTf} / \mathrm{X} 8$ battery. 


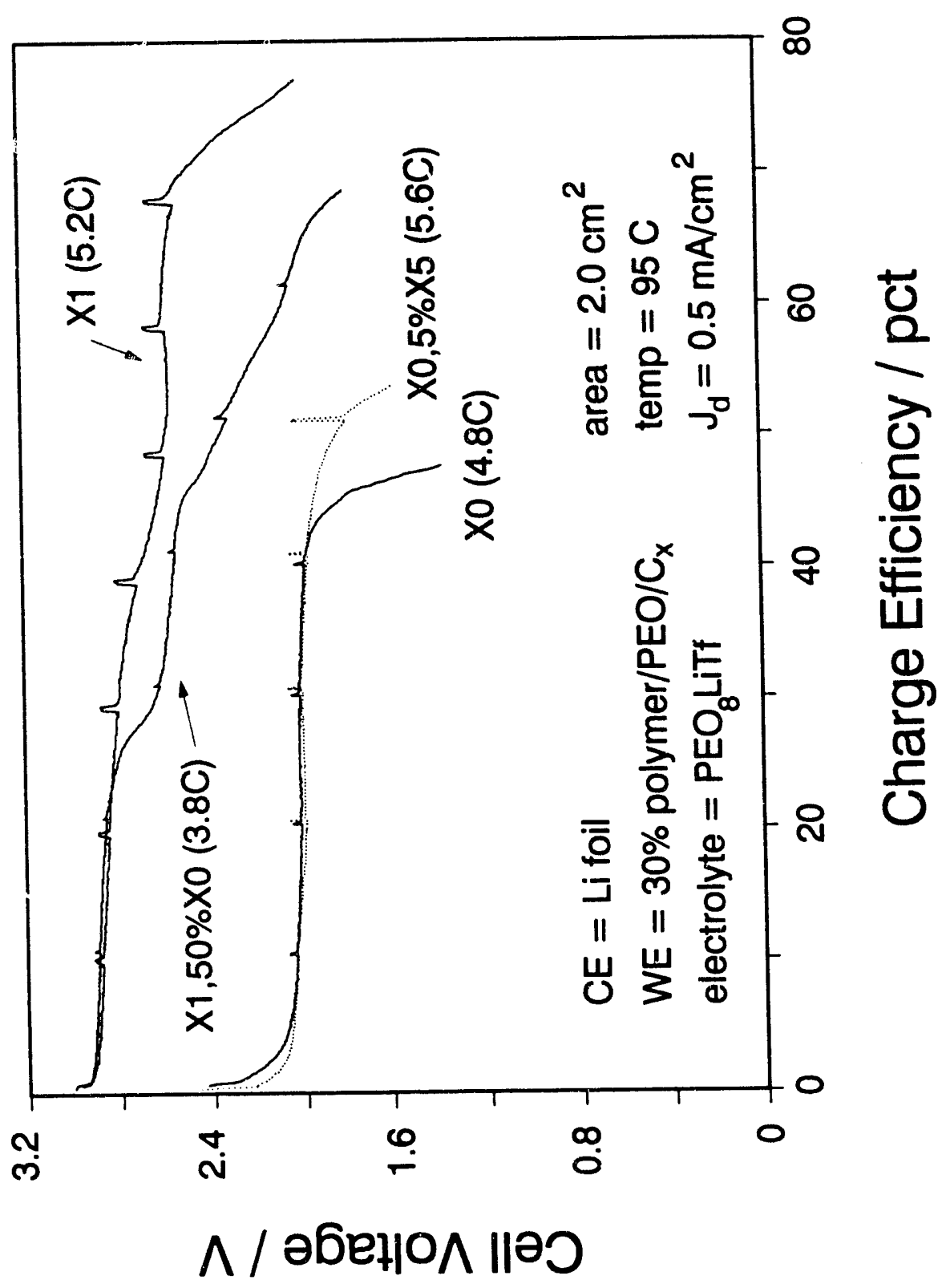

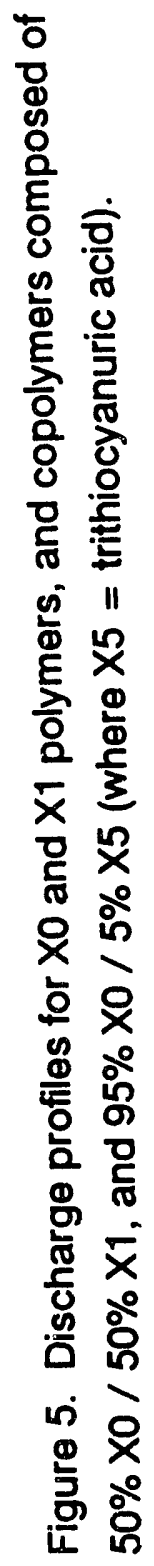



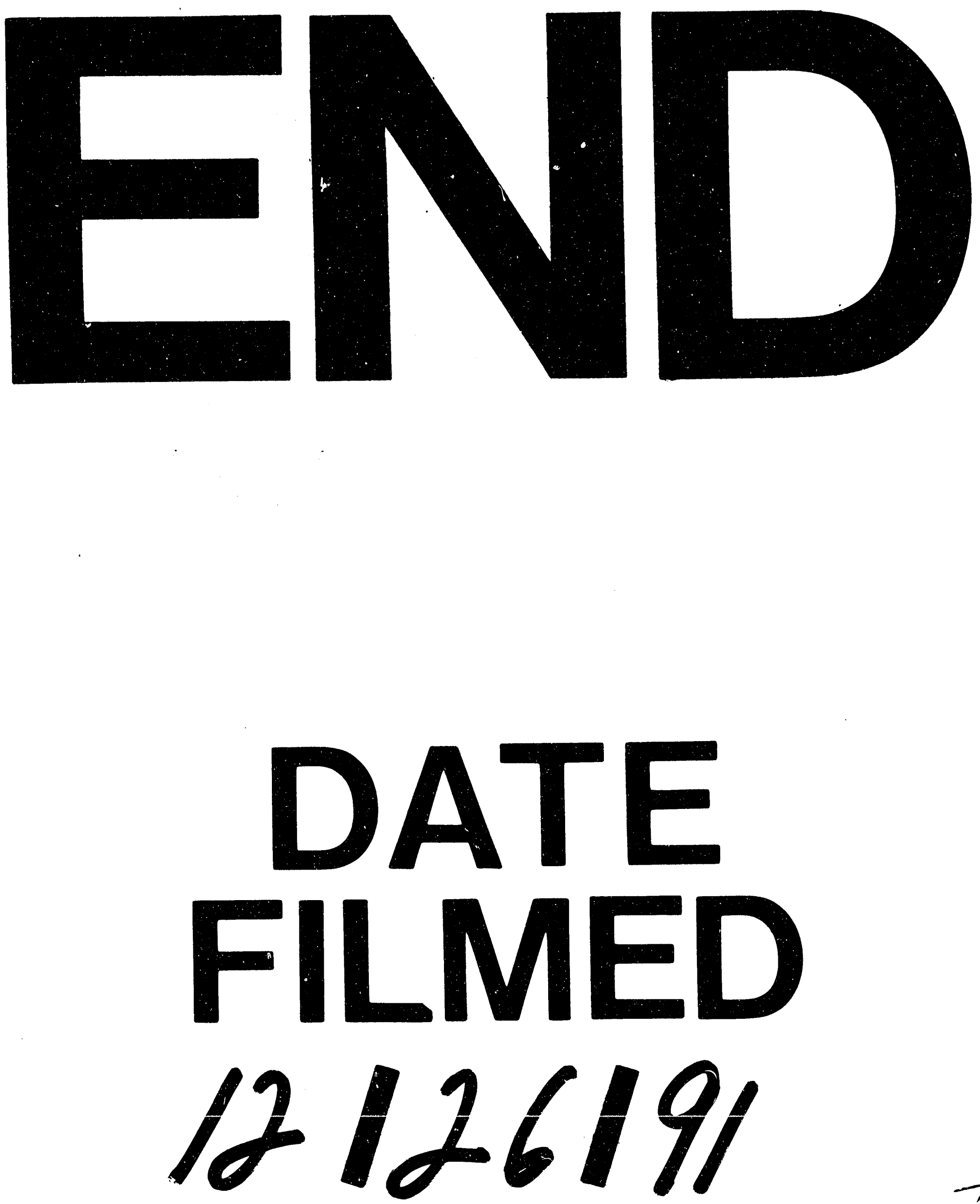
